\title{
Analysis on the "High Send and Transfer" Dividend Policy of Listed Companies in China
}

\author{
Yuhan Zhu ${ }^{1, *}$, Yitao Ding ${ }^{2}$ \\ ${ }^{1}$ Zhejiang University of Finance and Economics, Zhejiang 310018, China \\ ${ }^{2}$ Central University of Finance and Economics, Beijing 100081, China \\ *Corresponding author. Email: 13957912180@163.com
}

\begin{abstract}
China's capital market is developing constantly, but there are still many problems. This paper focuses on the phenomenon of high transfers that exist and has received a lot of attention in the Chinese capital market. Through theoretical research and literature induction methods, this paper first studies the reasons behind the high transfers of listed companies, that is, the increased liquidity hypothesis, the price illusion hypothesis, and the equity expansion hypothesis. Secondly, this behavior is often a tool for company executives or major shareholders to harvest the interests of shareholders. Based on this, this article puts forward suggestions that listed companies do not need to speculate on high prices and keep confidential information strictly; shareholders should independently strengthen the quality of investment; regulators should promote shareholder education and reasonably regulate the behavior of listed companies.
\end{abstract}

Keywords: "high send and transfer" dividend, listed company, dividend policy, excess return, abnormal return

\section{INTRODUCTION}

In recent years, China's equity financing market has developed vigorously and achieved great results, but there is still a certain distance in maturity compared with the capitalist markets of foreign developed countries. Therefore, many issues need to be explored and standardized. In the past ten years, there have been many high-delivery behaviors of listed companies in the Chinese market, which have become hot speculation targets in the market and have attracted market attention. This article explores the reasons, logic, and driving forces behind this kind of high transfer behavior, and further, analyze the problems that this phenomenon will bring, and finally make suggestions for all parties. This research can not only analyze and explain the phenomenon of high transfers for investors, but more importantly, it also can promote the mature development of the capital market by guiding all parties in the capital market.

\subsection{The Definition of High Delivery}

"High-send transfer" generally refers to a relatively large proportion of the payment method of giving away shares or using accumulation funds to increase the share capital, but scholars have certain differences in the definition of its degree. Some scholars believe that the transfer of 10 shares or more for every 10 shares is called "high-send transfer", and some scholars believe that the transfer of 5 shares or more for every 10 shares is called "high-send transfer".

After the "high send and transfer", although the company's total share capital has expanded, the company's shareholders' equity will not increase as a result.

\subsection{Reasons for the Existence of the High Send and Transfer Dividend Policy}

\subsubsection{Liquidity hypothesis}

Lowering the stock price can increase the liquidity and turnover of stocks, and also lower the investment threshold for investors [1]. Whether it is the improvement of liquidity or the lowering of investment threshold, it will prompt many individual investors to hold company stocks, and this is what the managers of listed companies hope. Therefore, the managers of listed companies use the "high send and transfer" 
method to reduce stock prices, and this phenomenon is more common in listed companies with high stock prices.

\subsubsection{Price illusion hypothesis}

The "price illusion hypothesis" believes that some investors will have price illusions due to the transfer behavior of listed companies [1]. It is believed that after the transfer, the price of stocks will decrease, and the room for stock prices will increase. It is precise because of this psychology that these investors are more inclined to buy "high-send transfer" stocks. Therefore, after being aware of the existence of investor price illusions, rational listed company managers will reduce stock prices as much as possible, and "high send and transfer" is undoubtedly the most convenient and effective way to reduce stock prices.

\subsubsection{Equity expansion hypothesis}

Especially for companies with small equity, the risk of being acquired and controlled is higher. [1] To reduce risks, company executives tend to substantially expand equity. Also, expanding the scale of equity will help to coordinate capital operations such as private placement and allotment of new shares to provide space for the company's comprehensive capital operation.

\subsection{Economic Consequences of High Send and Transfer Dividend Policy}

The economic consequences caused by "high delivery" stocks are various. There are both advantages and disadvantages in both the market and the company itself. The following are respectively analyzed from the perspective of the market and the company.

\subsubsection{Internal consequences (company)}

It distorts of the value orientation of corporate governance. [2] According to the agency cost theory, the distribution of dividends can reduce the agency cost and protect the interests of the principal. The owner entrusts the company to the operator to carry on the management, but between the principal and the agent may have some interest conflict. The short-term behavior of "high send and transfer" is a typical example. And therefore, in order to get the excess profit of cash out after the lifting of the restricted shares, the company's executives quit their positions after the successful listing of the company. Obviously, this kind of short-term behavior is contrary to the goal of maximizing shareholders' equity, and will greatly damage the stable growth and future development of the company.

It expands the company's equity and has a dilution effect. Although the implementation of the "high send and transfer" policy does not increase the owner's equity, it makes the company's share capital expand. In this way, when the growth of performance is not enough to support the expansion of share capital, "high send and transfe" will dilute the relevant financial indicators of the company, making its earnings per share decline. At the same time, it will face the risk of reducing earnings per share again due to the asynchronous growth of net profit and equity expansion in the next year.

\subsubsection{External consequences (market)}

It adjusts stock prices and is conducive to market transactions. [3] As mentioned above, the ex dividend and dilution after "high delivery" reduces the stock price and PE ratio, and lowers the investment threshold, thus promoting the circulation and trading of stocks. Reducing the market price per share through "high delivery" also greatly alleviates the pressure and impact on the market after the lifting of the ban of restricted shares.

The process of the high send and transfer will harm the rights and interests of investors, especially retail investors. The high send and transfer behavior is essentially a equity splitting behavior, which cannot bring any shareholder rights. In the current Chinese market, high forwarding behavior is often regarded as a signal of rising stock prices, leading to the entry of irrational investors. Therefore, company executives will take advantage of this phenomenon and information asymmetry to profit from stockholders, such as the more common behavior of executives to reduce their holdings after the transfer. These behaviors will greatly damage the interests of stockholders and are also not conducive to the soundness of the capital market.

\subsubsection{An example: Hareon Solar}

Here is an example. Hareon Solar Technology Co. Ltd., mainly engaged in photovoltaic-related businesses, was funded and established by the Ren Xiangdong family in April 2004. On January 23 2015, it issued an announcement "Proposal for Distribution of profits and using accumulation funds to increase the share capital of Hareon Solar in 2014 " that declared an extra 10 shares will be transferred to all shareholders for every 10 shares using capital reserve, on the basis of the share capital of Hareon Solar on December 31 2014. In addition, in respond to the inquiry from the Shanghai Stock Exchange, one big stakeholder Yang Huaijin announced that he would sell no more than 34.53 million shares over the next 12 months starting from January 22, 2015. Another two big stakeholders Jiurun Pipe Group and Zijin Electronics Group both replied that they would reduce their holdings in the next 12 
months by means of agreement transfer, bulk trading and secondary market trading and others.

Facing these information, individual investors irrationally pursued "High Send and Transfer" stocks and ignored the hidden risks, so the announcement of high send and transfer of Hareon Solar attracted a large number of irrational investors and pushed up the stock price in a short time. On January 23, 2015, the stock of Hareon Solar rose at 10.31 yuan, up by $10.03 \%$, but it fell sharply to nearly $17 \%$ in the next three days. What's more, the company had received several letters of inquiry and investigation notices. On February 132015 , the company's share price has fallen by about $25 \%$ and finally, in the evening of May 17 2019, the Shanghai Stock Exchange decided to terminate the company's stock listing. This behavior means that shareholders' executives try to manipulate the stock price to gain their own benefits through this kind of behavior, greatly violating our country majority shareholder's interest.

\subsection{Suggestion}

\subsubsection{To the listed company}

First of all, the listed companies should combine a series of factors such as their own development goals and operating conditions to formulate appropriate dividend distribution policies, rather than to meet the needs of investors in the market or other purposes. This will affect the normal development of listed companies, affect the relevant rights and interests of investors, or even have a certain impact on the normal operation of the securities market. [4] Secondly, companies should improve the quality of information disclosure, because many investors' investment analysis is based on the effective analysis of the information disclosed by the company. A series of market manipulation by using high price transfers is formally based on the misunderstanding of investors about the lack of detailed information disclosure. If listed companies improve the quality of information disclosure, investors can judge the company's trend more accurately and reduce blind investment.

\subsubsection{To investors}

It is necessary for investors to improve investment literacy and strengthen their understanding of the company's dividend policy, and do not blindly pursue the rise and fall of the concept stocks of "high send transfer". Based on understanding the dividend policy of listed companies and the concept of " high send and transfer", investors should also combine with the company's fundamentals, after careful analysis, and invest in the "high send and transfer" stocks with strong financial evidence. [5] And therefore, investors should invest rationally and learn to analyze from a long-term perspective and pay more attention to the basic situation of listed companies and conduct effective value analysis on these companies, so as to judge whether the stock has investment value, rather than short-term speculation.

\subsubsection{To Supervisor}

First of all, the supervisor of the securities market education for investors should be strengthened. At present, there is a large group of retail investors in my country's securities investors. These retail investors only have a little knowledge of the securities market, and they devote themselves to the stock market in an attempt to obtain excess returns from it. Therefore, they have a strong tendency to speculate on "high send and transfer" stocks. Because of this speculation, the risk education of retail investors should be strengthened to improve their correct understanding of the company's dividend policy, not to blindly participate in all kinds of blind hype about high rewards, and to guide them to establish long-term value investment concepts. [6] Secondly, it is necessary to correctly formulate regulatory measures for relevant dividend policies. Regulator should crack down on a series of illegal behaviors such as stock price manipulation and insider trading of listed companies, constantly improve the market supervision mechanism, and better maintain the effective operation of market mechanism, creating a good ecological environment for the development of capital market. [7] Thirdly, regulators should regulate the information disclosure mechanism of listed companies. At present, some disclosure of China's Listed Companies about relevant information of high send and transfer is not descripted in detail or concealed intentionally, which will not only mislead consumers, but also allow some listed companies to take advantage of this loophole to cash in. [8]Therefore, the regulatory authorities should require the listed companies to make clear instructions on the specific contents and whether they meet the requirements of the company's future development when disclosing the information of high-level transfer. Only when the relevant information of high-level transfer is fully disclosed, can investors have a better understanding of the company's value, so as to avoid blind investment.

\section{CONCLUSION}

Through the previous research, the reasons for the existence of the "high send and transfer" dividend policy are analyzed in three aspects. First, the high-transfer policy increases the liquidity of stocks and can increase the stock price; second, the "high send and transfer" dividend policy reduces the stock price and causes the stock price to rise expectation; third, high transfer policy can reduce company risks and increase space for capital operations. However, this phenomenon 
often exists in the situation that shareholders' rights are harvested by major shareholders or executives. Therefore, this article puts forward suggestions for all parties. For listed companies, they must not use high transfer speculation, and must also protect the confidentiality of the news; for investors, they need to strengthen the quality of investment and not blindly invest; for regulators, it is necessary to strengthen investor education and regulate the behavior of listed companies.

\section{ACKNOWLEDGMENT}

First of all, I would like to thank Professor Sun of Johns Hopkins University who taught me the knowledge of dividend policy of listed companies. She gave me lots of academic guidance and improved my understanding of the professional knowledge of corporate dividend decision-making. Secondly, I would like to thank the teaching assistants and thesis teachers for their great help in the topic selection and writing of papers. Finally, I would like to express my gratitude to my classmates. During the study, I did some case studys with them and interacted with them in class, so that I can master the knowledge more thoroughly.

\section{REFERENCES}

[1] T. Cheng, Research on the phenomenon of the "high send and transfer" in China's stock market, 2016

[2] J. Zhu, The market effect and motivation of the" high send and transfer", 2019

[3] X. Li,Research on the phenomenon of "high send and transfer" in China's stock market, 2014

[4] P. Zhao,A study on the motivation and market reaction of listed companies' "high send and transfer", 2014

[5] D. Xie, "high send and transfer" of listed companies and insider stock reduction, 2016

[6] P. Hang, Research on the "high send and transfer" dividend policy of high growth companies, 2018

[7] X. Qian, The motivation of listed companies to "high send and transfer", 2016

[8] Z. Qian, A study on the market performance and specific causes of the "high send and transfer" behavior of China's A-share listed companies, 2016 